\title{
17p11.2 microduplication syndrome
}

INSERM

\section{Source}

INSERM. (1999). Orphanet: an online rare disease and orphan drug data base. $17 p 11.2$ microduplication syndrome. ORPHA:1713

17p11.2 microduplication syndrome is a rare chromosomal anomaly syndrome, resulting from the partial duplication of the short arm of chromosome 17, typically characterized by hypotonia, poor feeding, failure to thrive, developmental delay (particularly cog nitive and language deficits), mild-moderate intellectual deficit, and neuropsychiatric disorders (behavioral problems, anxiety, attention deficit hyperactivity disorder, autistic spectrum disorder, bipolar disorder). Structural cardiovascular anomalies (dilated aortic root, bicommissural aortic valve, atrial/ventricular and septal defects) and sleep disturbance (obstructive and central sleep apnea) are also frequently associated. 